\title{
EL TRAVESTISMO Y LA ANDROGENIZACIÓN EN LAS FIES- TAS DE MOROS Y CRISTIANOS. Una mirada desde la dimensión dialógica
}

\author{
Miguel Ángel MARTíNEZ POZO \\ Universidad de Jaén \\ miguelangelmartinezpozo@gmail.com
}

\begin{abstract}
THE TRAVESTISM AND THE ANDROGENIZATION IN THE HOLIDAYS OF MOROS AND CHRISTIANS. A look from the dialogic dimension
\end{abstract}

Resumen: Las fiestas de moros y cristianos, en las últimas décadas del siglo XX y entrado el siglo XXI, han evolucionado hacia una búsqueda de valores contemporáneos donde, poco a poco, de manera subconsciente por parte de sus protagonistas, han ido rompiendo y erradicando estereotipos pre construidos e institucionalizados e introduciendo aspectos y cambios acordes con los momentos en los que vivimos. Hoy día, la fiesta, como soporte de las artes, está íntimamente ligada a las artes escénicas y plásticas donde se establece una performance artística. A través del siguiente artículo nos introduciremos en los tipos de travestismos existentes dentro de las fiestas de moros y cristianos e incluso en la propia androgenización como parte de un engaño, simulación, simulacro o como mera necesidad de transformarse para subsistir o bien integrarse dentro de la propia fiesta.

Abstract: Throughout the latest decades of the twentieth century and up to the twenty first century Moors and Christians Festivals have evolved towards more contemporary values. Its participants have gradually and unconsciously broken and eradicated institutionalized stereotypes introducing and adapting to present-day developments. Today these festivities are intimately associated to performing and plastic arts where an artistic representation is established. My present essay will discourse on types of cross-dressing within Moors and Christian Festivals and even the pretended androgyny as part of a deception or simulation or as a mere necessity to transform conducive to subsisting and becoming part of the festival itself.

Palabras clave: Artes Escénicas, Artes Plásticas, Travestismo, Moros Y Cristianos, Androgenización Performing Arts, Plastic Arts, Cross-Dressing, Moors And Christians, Androgyny 


\section{Introducción}

A pesar de todas las peculiaridades que envuelven a la sociedad posmoderna y actual, las fiestas de Moros y Cristianos, hacen que los miembros de una sociedad determinada posean un sentimiento de pertenencia que le hacen identificarse. En muchas ocasiones es poco entendible por otras personas externas cómo ese sentimiento que envuelve a sus miembros les hace poseer un tipo de identificación social por su manera de vivir, comprender y percibir la vida entorno a una comunidad: su comunidad. Víctor Turner usa el término communitas para referirse a un modo particular de relaciones sociales en un área determinada de individuos que llevan una vida común (Turner, 1988). Sea el pueblo que sea, las fiestas de Moros y Cristianos se viven en comunidad, con sus peculiaridades y características que dependerán de su heterogeneidad, pero con cierta conexión los unos con los otros porque conviven sus miembros compartiendo elementos cognitivos comunes (Martínez, 2015b: 88).

En las fiestas de moros y cristianos se genera una dialéctica constante de cambio y continuidad, ya que la tradición se mantiene en su estructura y elementos fundamentales, al tiempo que cambia en sus formas, debido a influencias externas. Y eso es positivo pues, al igual que la propia sociedad, la fiesta enfermaría cuando se dejase de cuestionar. Tal y como nos expresa Cornelius Castoriadis (Cit. por Z. Bauman):

"No puede ser de otro modo, si se considera que - lo sepa ella misma o nola sociedad es autónoma (sus instituciones están hechas por los hombres y, por eso mismo, los hombres pueden deshacerlas), y que la suspensión del cuestionamiento elimina la conciencia de esa autonomía, promoviendo la ilusión de heteronomía con sus inevitables consecuencias fatales. Reanudar el cuestionamiento significa dar un paso muy grande hacia la cura. Así como en la historia de la condición humana el descubrimiento equivale a la creación, y en el pensamiento humano explicar y entender son la misma cosa, en los esfuerzos por mejorar la condición humana, diagnóstico y terapia coinciden" (Bauman, 2010: 225).

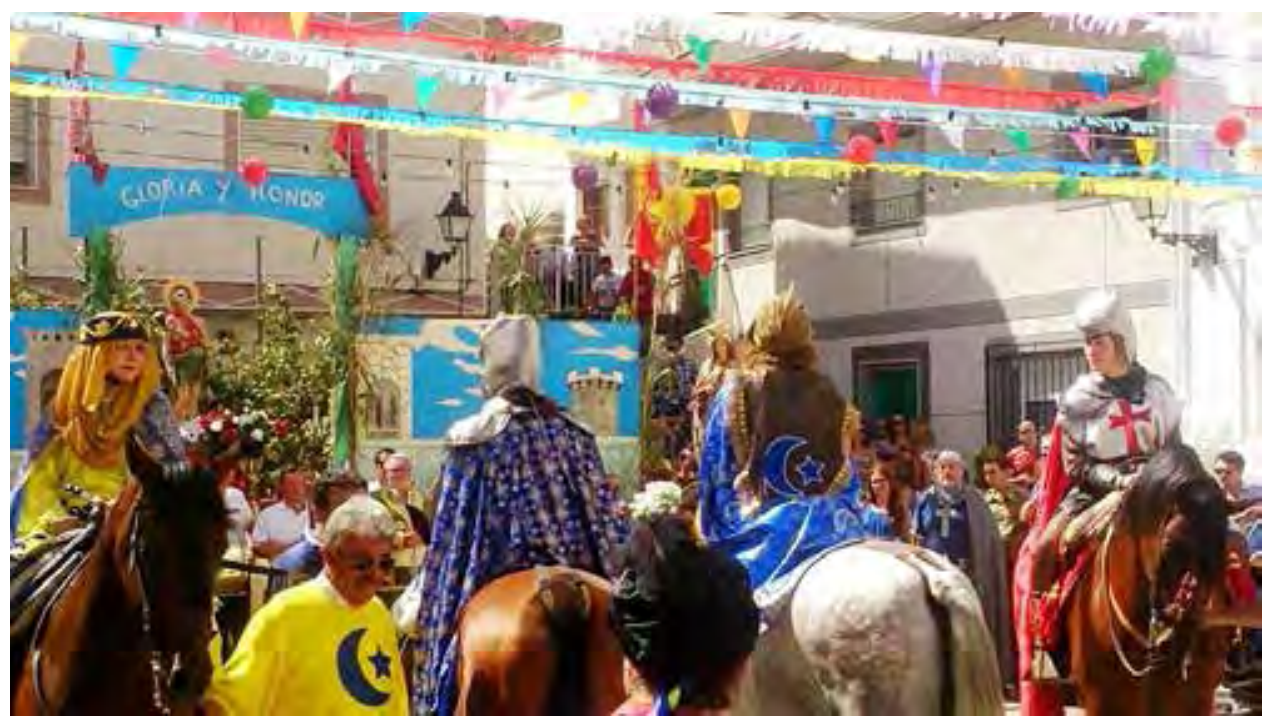

Relación de Sierro, integramente representada por mujeres en el año 2016. Foto Adrián de Manuel 


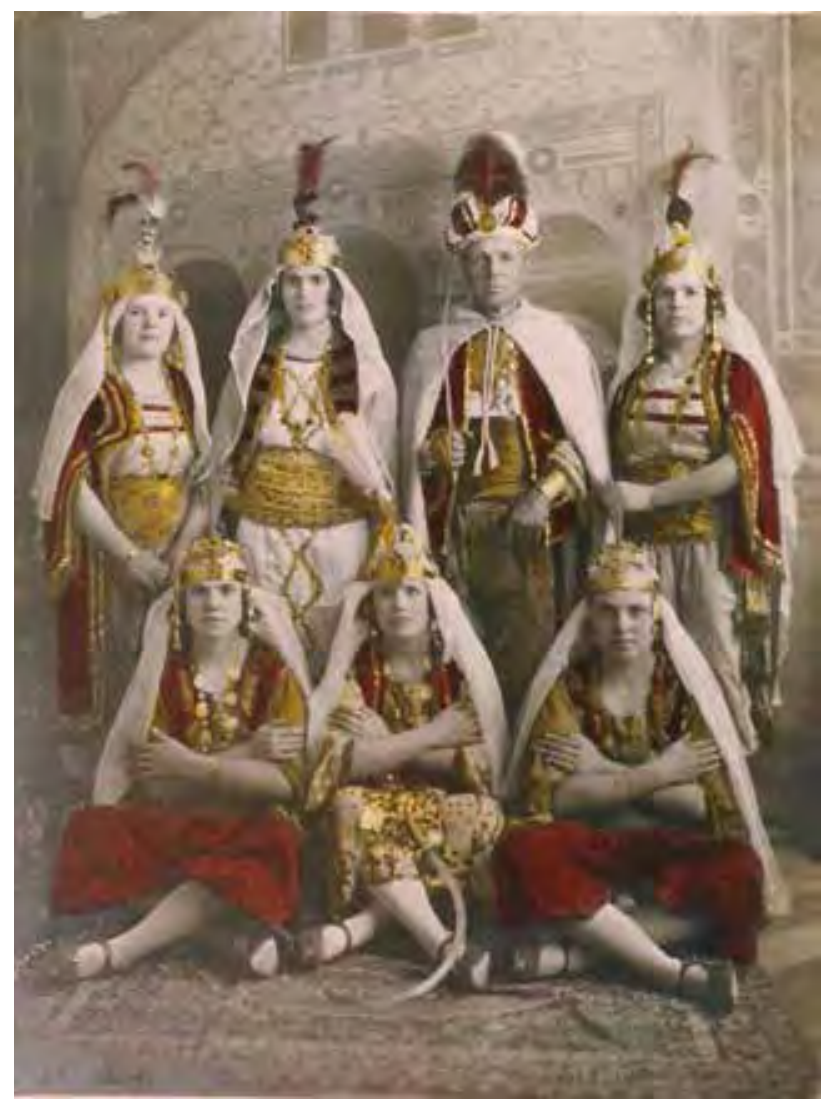

Filà Llana 1927 Capitán y mujeres en Muro (Alicante). Archivo Pascual Gisbert, J.J. y Mengual Fitor, M.J.

La complejidad estructural de la fiesta de moros y cristianos hace que esta se impregne de múltiples valores culturales y patrimoniales que forman en sí mismos un entrelazado donde se sincretizan diferentes actos y elementos.

\section{II.- La fiesta como performance artística}

Las fiestas de moros y cristianos, dentro de su entramado complejo y el incrustamiento de los diferentes elementos (culturales, artísticos o sociales) se desenvuelve en torno a un espacio escénico donde el orden de la vida cotidiana es roto por el caos entendido desde la arbitrariedad y el azar. Las calles y los diferentes lugares de la población se convierten en sitios donde caben todas las posibles contingencias; los desfiles se convierten en caprichos estéticos-formales en los que, por medio de un juego musical, la corporalidad a través del movimiento rítmico al son de unos timbales invade a quienes van vestidos con su indumentaria festera. Pero, a su vez, se establece un juego dramático imponiendo que la comunidad crea lo que observa como parte de los elementos que (sacralizados) les identifican (Martínez, 2015). El espacio público se convierte en un lugar con un contenido específico al paso del desfile o de la imagen: se reafirma como un lugar importante y crucial. Tal y como argumenta Anta Félez:

"El espacio no cambia porque tenga la posibilidad de hacerlo (en definitiva, porque lo marca la tradición festiva), sino porque la posibilidad de hacerlo le es asignada por el contenido que se le ha dado a lo que allí ocurre" (Anta, 2003: 68). 
Y dentro de ese espacio donde pasa un desfile, la procesión, donde se recrea la batallas, donde se representa la comedia, embajada o auto sacramental o donde las personas disfrutan de la fiesta nocturna se crea un sinfín de expresiones, emociones, dramatizaciones arbitrarias y acciones del individuo o grupo en un lugar determinado y durante un tempo que podríamos definir como la posibilidad de la fiesta de ser una performance artística.

"Un modo de comprender la escena de este mundo confuso, contradictorio y extremadamente dinámico, es examinarlo "como performance". Y eso es precisamente lo que hacen los estudios de la performance. Los estudios de la performance utilizan un método de "amplio espectro". El objeto de esta disciplina incluye los géneros estéticos del teatro, la danza y la música, pero no se limita a ellos, comprende también los ritos ceremoniales humanos y animales, seculares y sagrados; representación y juegos; performance de la vida cotidiana; papeles de la vida familiar, social profesional; acción política, demostraciones, campañas electorales y modos de gobierno; deportes y otros entretenimientos populares; psicoterapias dialógicas y orientadas hacia el cuerpo, junto con otras formas de curación (como chamanismo); los medios de comunicación. El campo no tiene límites fijos” (Schechener, 2000: 12).

El espacio público se convierte en un soporte del arte donde se despliega la creatividad y, dentro de él, el cuerpo de protagonistas y espectadores se conforman como el principal soporte de la performance.

"Fuera de los actos oficiales la calle ofrece el espectáculo de una fiesta alegre y desordenada, con grupos desfilando de manera improvisada tras una música, sus festeros con los trajes cada vez más desaliñados, las botellas circulando de

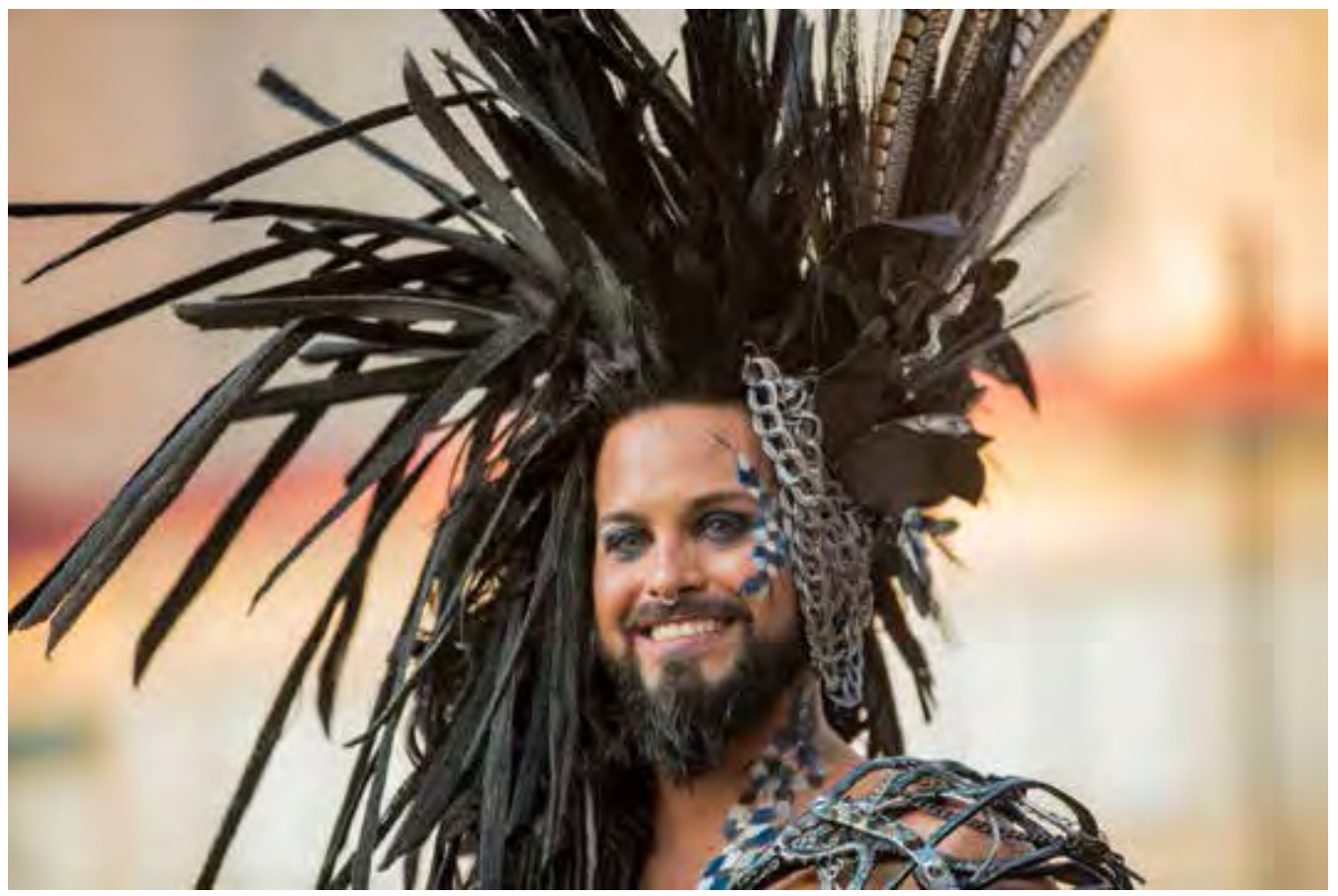

Hombre en las fiestas de Elda (Alicante). Xe que foto. 


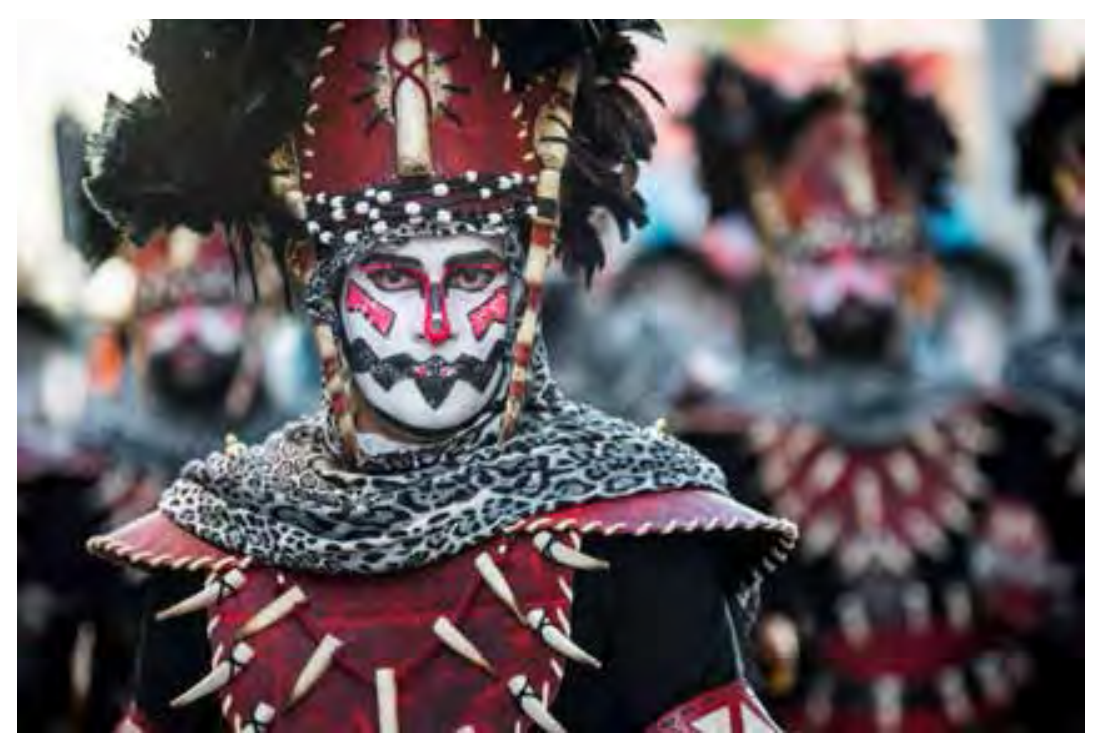

Filá de Negros en San Vicente del Raspeig (Alicante). Xe que foto.

mano en mano. Las mismas escenas se reproducen en las sedes de las compañías" (Jean-Pierre, 2003: 98). Este hecho es algo que ocurre en cualquier fiesta a la que el espectador vaya donde incluso él mismo, al entrar en este juego, forma parte de la comunidad y es así cómo, existen actos de la propia programación en los que se difumina la frontera entre protagonistas y espectadores dejando estos últimos de ser sujetos pasivos para que, con su actividad, sea alcanzada una liberación a través de la expresión emotiva y la representación colectiva. Es decir, no solo las fiestas son parte de una performance de la comunidad, sino también de un happening y, hay que dejar claro que, aunque en muchos casos son confundidos estos términos, el happening difiere de la performance por la improvisación o, mejor dicho, por la imprevisibilidad.

A su vez, entrada ya la democracia y una vez salidos de la dictadura, el pueblo ve la fiesta, o la percibe como "sinónimo de libertad, de espontaneidad, de apropiación de los espacios públicos [...], como una esfervecente communitas antiestructural y sociable" (Homobono, 2004: 37) Los jóvenes ofrecen una pasión por sus fiestas. Son los primeros en sacar su traje, su chilaba y colocársela. Realmente son los que más la disfrutan ya que, si a ello le sumamos las nuevas tecnologías con las que cuentan actualmente (internet, teléfonos móviles y redes sociales) podemos decir que son parte del impulso de la fiesta hoy día. Pero anteriormente, sus padres, de acuerdo a las características sociales y avances de su época, también lo fueron. Gil Calvo, E. expone que esa pasión de los jóvenes por las fiestas y, por lo tanto, por su fiesta puede ser debido a que encuentran:

"Algo que su realidad social les negaba, quizá: el reconocimiento y exaltación de su libertad personal desde la coacción tácita e informal que ejerce el medio social hasta la espuria satisfacción de los intereses arribistas, pasando por la pura y simple búsqueda de la gratificación y el placer corporal [...]. Si la fiesta embriaga es porque emborracha de libertad. Entregarse a la fiesta es emanciparse, liberarse, desencadenarse y desprenderse de cualquier atadura anterior o vinculación previa [...]. Huyes del oscurantismo y huyes del poder 
que te sujetan, asociados al vigente orden social de tu familia, tu trabajo y tu comunidad [...]. Gracias a la fiesta, puedes eludir el poder del poder [...] la imposible pero perfecta utopía de la fiesta permanente e indefinida" (Gil, 1991: 120-124).

En las fiestas de moros y cristianos se respira aire de libérrima libertad donde el cuerpo traspasa sus propios límites desafiando los estereotipos establecidos existiendo una metamorfosis, desplazamientos o un diálogo donde, a su vez, hombres y/o mujeres se travisten e incluso se androginizan, se produce un camuflaje, simulación o engaño vistiéndose incluso el adulto de niño, el ser humano de seres mitológicos, de animales e incluso de la propia naturaleza.

\section{III.- El travestismo en las fiestas de moros y cristianos}

Las fiestas de moros y cristianos son unas fiestas camaleónicas (Martínez, 2015: 318320) que han ido adaptándose a los diferentes momentos históricos vividos y que, en cierta manera y, a pesar de la búsqueda de una historicidad, entrada la postmodernidad, se ha abierto el camino a un juego de fantasía y multicolor donde las artes plásticas y escénicas han tomado gran importancia: podríamos decir que las fiestas son un soporte del arte (Anta y Martínez, 2015: 84-97). En ellas, el travestismo ha tenido cabida descodificando "unas leyes y creencias atávicas que, una vez transcurridos los pocos días de alborozo, volverán a reimplantarse. Pero hasta tanto eso no suceda, el desenfreno, la abolición de privilegios, de reglas y tabúes, el espíritu de radicalismo utópico invadirá los espacios públicos, y la importancia de la vida material y corporal se coloca en el punto de mira" (Gutiérrez, 2009: 87).

El arte, como medio intrínsecamente ligado a la vida del ser humano, es un medio de expresión y un lenguaje universal que ha prevalecido a lo largo de la historia mostrándonos

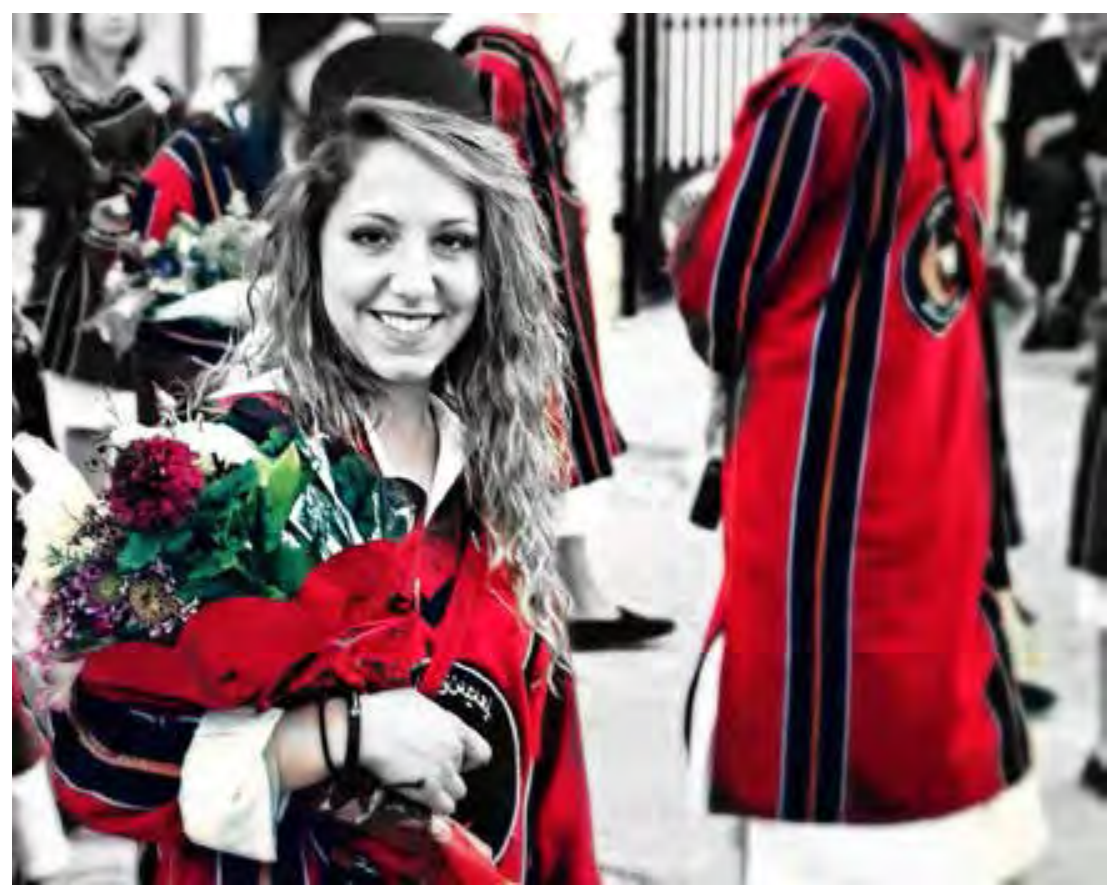

Comparsa Pakkos del Guardal en Benamaurel (Granada). FotoMónica Parra 


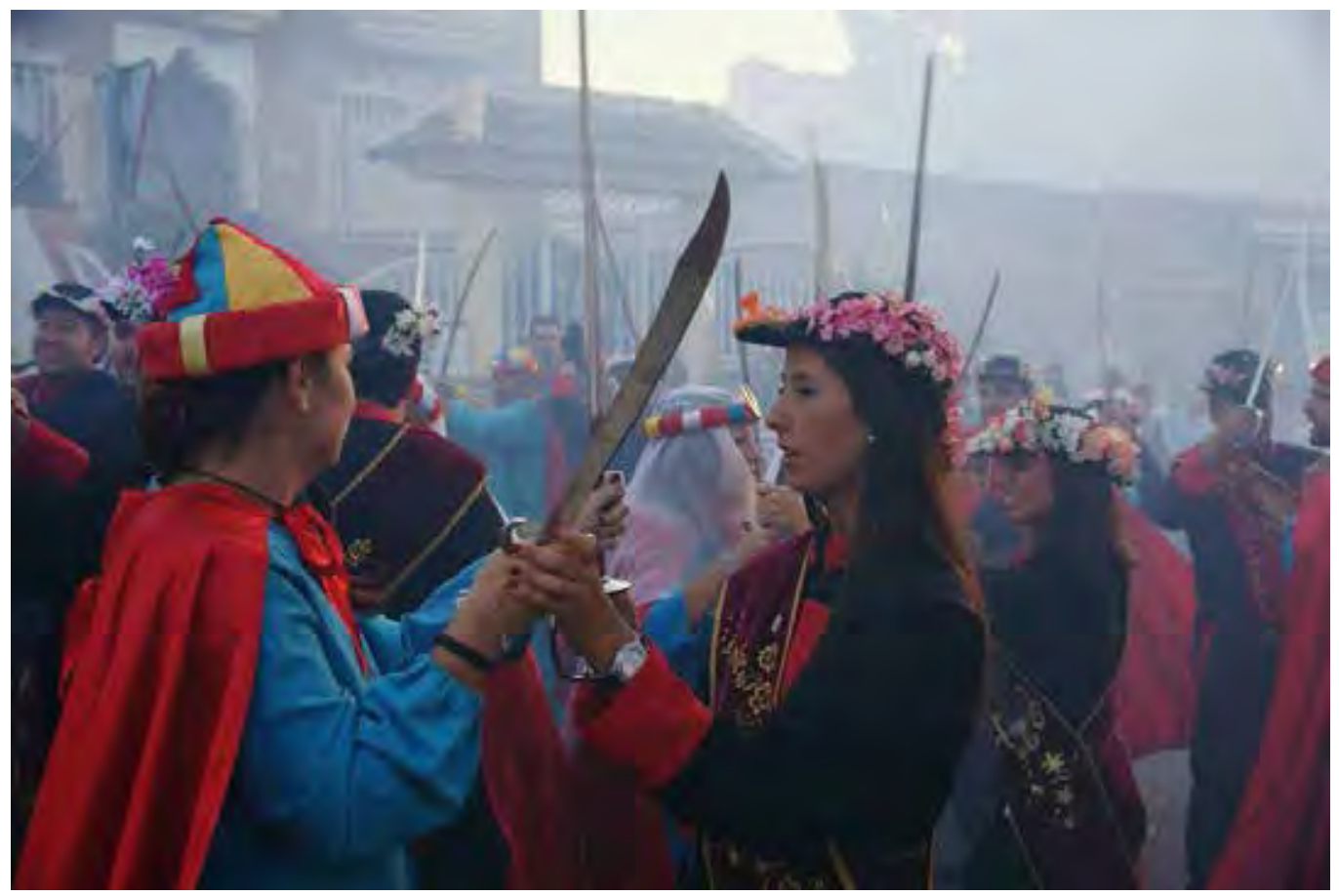

La mujer en las fiestas de Campillo de Arenas (Jaén). Foto Federico Valverde

diferentes visiones estéticas. Tal y como nos expresa Óscar Wilde, este es producto de la imperfección de la Naturaleza cuya pluralidad no se halla en esta misma "sino en la imaginación, en la fantasía o en la ceguera cultivada de quien la contempla" (Wilde, 1987: 131). Quizás, no hay mejores palabras que las expresadas por este dramaturgo, poeta y escritor irlandés:

“¿Qué es la Naturaleza? No es la madre que nos dio la luz: es creación nuestra. Despierta ella a la vida en nuestro cerebro. Las cosas existen porque las vemos, y lo que vemos y cómo lo vemos depende de las artes que han influido en nosotros. Mirar una cosa y verla son actos muy distintos. No se ve una cosa hasta que se ha comprendido su belleza. Entonces y sólo entonces nace a la existencia" (Wilde, 1987:131).

A través de las artes, llegan a tambalearse los cimientos a partir de los cuales se ha construido una sociedad falocentrista, heteronormativa y estereotipada a lo largo de los siglos.

"Los estereotipos con frecuencia son negativos y condenan, desprecian y banalizan a quienes nombran cayendo en el sexismo, el racismo, el clasismo y la homofobia. Los estereotipos contribuyen a la opresión, el prejuicio y la discriminación" (Palencia, 2008: 14).

Las fiestas de moros y cristianos, en las últimas décadas del siglo XX y entrado el siglo XXI han evolucionado hacia una búsqueda de valores contemporáneos (Martínez, 2015) donde, poco a poco, de manera subconsciente por parte de sus protagonistas han ido rompiendo y erradicando estereotipos pre construidos e institucionalizados e introduciendo as- 
pectos y cambios acordes con los momentos en los que vivimos. Hoy día, la fiesta está íntimamente relacionada con las artes escénicas, por un lado, a través de sus majestuosos desfiles, boatos, representaciones teatrales, bailarines y danzantes, los ballets, la música, etc.; y, por otro, con las artes plásticas, por medio de las lujosas vestimentas e indumentarias llenas de colorido, luz y contrastes en su pedrería y telas así como en el maquillaje de sus actores donde crean composiciones pictóricas en sus rostros llenándolos de inigualable belleza (Martínez, 2013: 128):

"A semejanza de la naturaleza, el arte es pródigo en técnicas simuladoras puesto que, por mucha "vida" que rezume, representa una fantasía a la que se llega desnaturalizando modelos reales, o intensificando éstos hasta hacerlos irreconocibles. El arte deconstruye los resortes del otro para exocisarlo a fin de reclamar su exterminio e instaurar su propia existencia verdadera" (Gutiérrez, 2009: 12).

La influencia del cine histórico, épico y, sobre todo fantástico así como el teatro contemporáneo ha creado figuras mitológicas que forman parte de los boatos, ballets, capitanías y, por consiguiente, de los desfiles estando carentes de rigor histórico y, más bien, formando parte de una nueva estética y cultura inmersa en la sociedad sutilmente a través de la televisión y nuevas tecnologías sin dejar a un lado la recibida por los artistas y escritores. ${ }^{1}$ Es aquí donde entra en juego la imaginación de dibujantes, diseñadores o literatos que, a través de sus ideas y creatividades, pueden llegar a desafiar a la propia comunidad, es decir, al propio colectivo festero, creando un gran abanico de posibilidades visuales con múltiples lecturas y significados iconográficos que ayudan incluso a romper las desigualdades sociales, de raza y de género. Se simulan animales, principalmente félidos (quizás por su carácter cazador tan relacionado con la fiesta y por su espectacular belleza y elegancia), también elementos de la propia naturaleza formando parte de las escuadras, tanto moras como cristianas pero, además, se llega a representar a la propia muerte (Martínez, 2015b: 92):

"La elaboración de imágenes es un impulso propio de los seres humanos, que se acentúa ante situaciones desconcertantes; la imaginación intenta transformar lo ininteligible en una representación que pretender hacer accesible a la compresión aquello que parece evadirla. En el caso de la muerte, ninguna imagen puede captarla en todo su significado, pese a los variados modelos provenientes de la mitología, folclore, religiones, giros idiomáticos, arte y literatura" (Duarte, 2008: 1).

A su vez, se han concebido, en las últimas décadas principalmente, seres andróginos donde el cambio intersexual de papeles se puede percibir en las Entradas y Desfiles. Este hecho hace que los propios protagonistas sean también espectadores fundiéndose ambos en uno mirando, observando, reflexionando y teniendo, a su vez, una experiencia estética, es decir "un modo de encuentro con el mundo o con los objetos y situaciones que nos hallamos en él, ya sean naturales o creados por el ser humano, que produce en quien lo experimenta un placer y un tipo de conocimiento peculiar en aquello que percibe o en aquello que comprende" (Roldán,2003:148). Pero hay que dejar claro que, la androgenización, no solo

1 A modo de ejemplo podríamos citar lo siguiente: ilustraciones del siglo XIX ya influyeron como es el caso de la filà Contrabandistas de Alcoy en 1830 quienes se inspiraron en dibujos del francés, grabador, escultor e ilustrador Gustavo Dorée. A principios de los años noventa, en Alcoy surge un tipo de traje inspirado en la película de Conan el Bárbaro. La música también ha bebido de la influencia del cine con adaptaciones como Titanic, Éxodo, Juego de tronos, entre otras (Martínez, 2015). 
se percibe en espectaculares trajes que llevan hombres o mujeres donde algunas veces las diferencias son ínfimas o nulas, sino también en maquillajes como juegos de fantasías y multicolor y en las gestualizaciones contrarias a lo estipulado por los ojos de los puristas.

Se crea, a su vez, un travestismo recreativo que forma parte de la diversión ocasional que la propia fiesta nos ofrece, nos aporta y que nos hace sentir, pensar, reflexionar y ver con una nueva mirada más abierta creando una metamorfosis de nuestros propios cuerpos como parte de una comunidad, ya que el individuo travestido se sentirá "parte indisoluble de la colectividad, miembro del gran cuerpo popular que evoluciona en medio de la locura [...] El individuo, en un juego doble, se impregna de la pluralidad de todos, liberándose de la pesada carga de una identidad limitada" (Gutiérrez, 2009: 91). Y es que, en pleno siglo XXI, en las fiestas de moros y cristianos de la mayoría de las poblaciones, durante sus días festivos:

\begin{abstract}
“estamos ante el monde à l'envers (el mundo al revés), momento caótico en el que las gradaciones sociales se suprimen, así como las formas de miedo, etiqueta, etc. relacionadas con ellas. Al mismo tiempo, las desigualdades de cualquier tipo (edad, sexo, etc.) entre los hombres simulan cancelarse. Desde la perspectiva bajtiniana, el tópico del mundo al revés es una gozosa celebración de la llegada de un sistema nuevo que pone patas arriba los viejos estamentos y confunde las apariencias [...] Se elimina toda individualidad, se disuelven las fronteras y, finalmente, se potencia la metamorfosis" (Gutiérrez, 2009: 88).
\end{abstract}

Todo ello es visible porque las fiestas son vividas en su originalidad y flexibilidad, dando respuestas a los problemas planteados por la normatividad y boato de la tradición (implorado por los puristas), deshaciendo la rigidez, el estereotipo y lo aparentemente inamovible. De la misma manera en la fiesta es observable su productividad y fluidez, desarrollando ideas y elaborando una aptitud de transformación, revisando lo que se conoce y produciendo pautas y formas muchas veces nuevas que ensalzan una renovada forma de ver y hacer la fiesta (Martínez, 2013: 128-130).

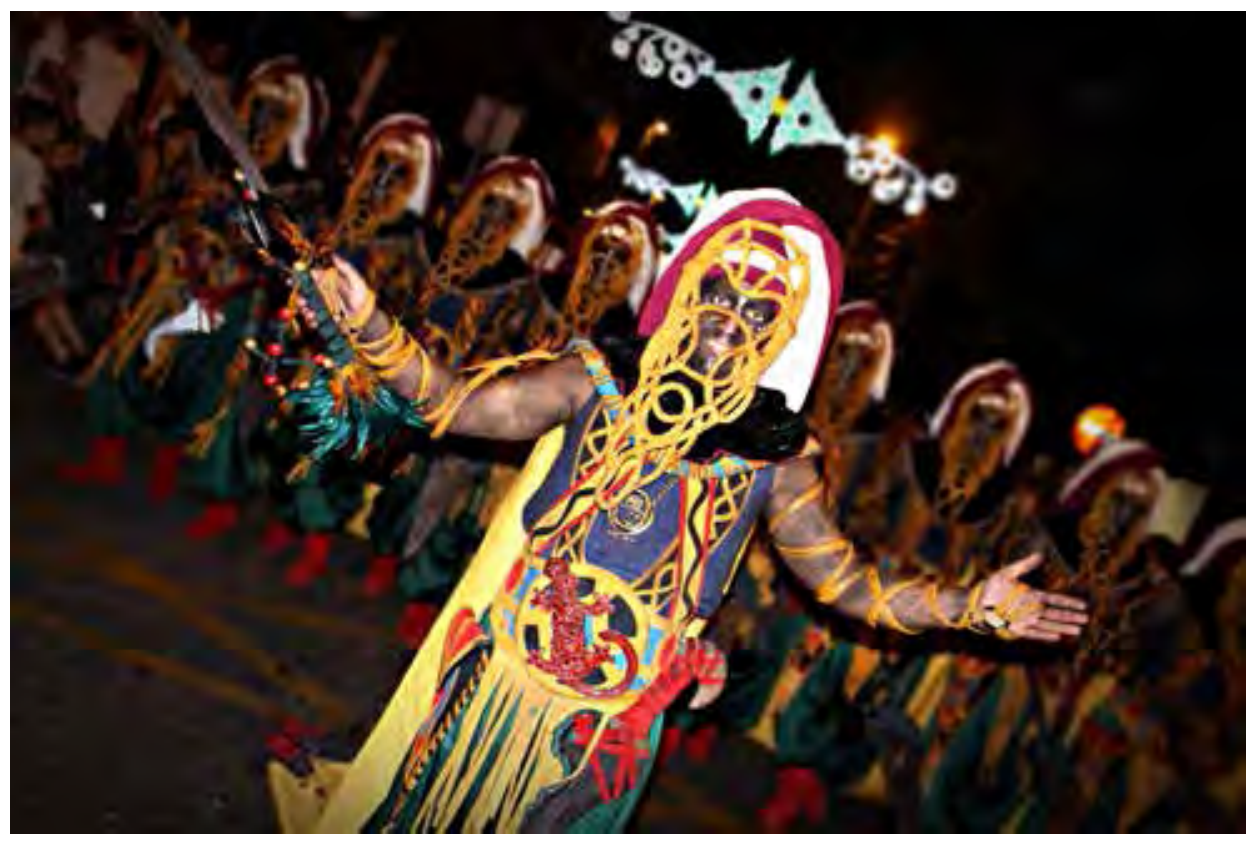

Escuadra Saladinos en Elche (Alicante). Xe que foto 
Se debe dejar claro que no es exclusividad del hombre el travestismo sino que también forma parte de la mujer aunque, bien es cierto que, en nuestra cultura de patriarcado forjada a lo largo de los siglos, observar una mujer con ropa de varón ha pasado de manera más o menos desapercibida mientras que, al contrario, ha ocasionado grandes rechazos sociales. Actitud de repudio por aquellos que defienden la permanencia de patrones inalterables culturalmente. Introduzcámonos en la mujer como travestismo estratégico.

España ha sido una sociedad jerárquica y clasista determinándose el lugar ocupado por el individuo a través de su sexo, estado civil y clase social. Discursos religiosos, científicos y políticos reconocían la inferioridad femenina, una creencia generalizada donde la mujer era un complemento del hombre siendo la resignación y sumisión norma de la vida de estas (Martínez, 2015c):

"El travestismo desde la mujer es una metáfora de poder, todo un símbolo desestabilizador en una sociedad cuyos papeles genéricos se consideran inalterables" (Garber, 1992: 9).

Considerada una fiesta de hombres por su carácter caballeresco vinculado al mundo de la caza y del servicio militar con reminiscencia guerrera se consideraba como natural que solo fueran los hombres quienes actuasen y representasen (Mansanet, 1974: 265-271). Aunque la presencia de la mujer en las guerras ha tenido poca historiografía tradicional, ya que durante la Edad Media las mujeres no estaban obligadas a ir excepto ante peligros inminentes donde la legislación preveía su concurso, es ciertamente curioso cómo, si quisiéramos darle una cierta historicidad a la fiesta, la participación de la mujer en la guerra siempre ha estado presente. Mujeres que "asumen funciones castrenses en determinados momentos, personajes virilizados al decir de una histografía que gustosamente las consignó” (Lorenzo, 2003). Es así el caso de la condesa de Evreux, Leonor de Antioquía, Jeanne de Montfort, Juana de Arco o las españolas María Pérez, que, vestida de hombre, batalló contra los musulmanes en el siglo XII y retó en un duelo al mismo Alfonso I el Batallador y Jimena Blázquez quien defendió la ciudad de Ávila de los musulmanes en 1109²; las mujeres de Quesada (Jaén) peleando armadas junto a sus maridos a finales del siglo XV; la condesa de Plasencia (Cáceres) ganando la villa de Alcántara (Carlé, 1988: 75) o Sayyida al-Hurra que "dentro de una sociedad de hombres, quiso ser ella misma el hombre con un comportamiento de tal y con desafío" (Gil, 2000: 311-320) entre otras. No debemos olvidarnos de los textos de Hurtado de Mendoza ${ }^{3}$ y, especialmente, el de Luis del Mármol ${ }^{4}$ en la rebelión de las Alpujarras así como, posteriormente a esta, autos de fe que verifican la participación de mujeres (Pérez de Colosia, 1989) pero tampoco de la literatura oral a través de romances como es el caso de

\footnotetext{
2 E Ximena Blázquez, con gran afán de no perder la ciudad, viajava de rúas en rúas, e de morada en morada contando las gentes, e vasteciéndolas de pan e carnes, faciéndolas plegarias non se fugiessen e que oviessen ossadía de bien defender su ciudad. E con pocos escuderos e de algunos homes, maguer non oviessen entera sanidad, fazía los repartimientos, e señalava onde avía cada home de velar e otear la arribada de los moros [...] Otrosí, repartió dardos, benablos, vallestones e toda la farina que se falló en la morada del señor obispo (Ariz, 1978).

3 Así nos encontramos con las moriscas de Alcudia donde se nos especifica lo siguiente: Hicieron (los moriscos) la defensa que pudieron con piedras y gorguces, porque en tanto número como 1500 hombres, había solo 40 arcabuceros y ballesteros. Fueron rotos, murieron muchos y con más pertinacia que los de otras partes; porque hasta las mujeres meneaban armas (Hurtado de Mendoza, 1970: 210).

4 Aunque este autor nombra la participación de la mujer en varias ocasiones haremos mención, como muestra de ello, en los siguiente párrafos donde se nos especifica la cruel muerte de un cristiano en Andarax por parte de las moriscas: Y lo llevaron arrastrando con una soga fuera del lugar y en un cerrillo lo entregaron a las moras, para que también ellas se vengasen, las cuales le sacaron los ojos con los cuchillos y lo acabaran de matar a pedradas (Mármol, 1991: 109).
} 


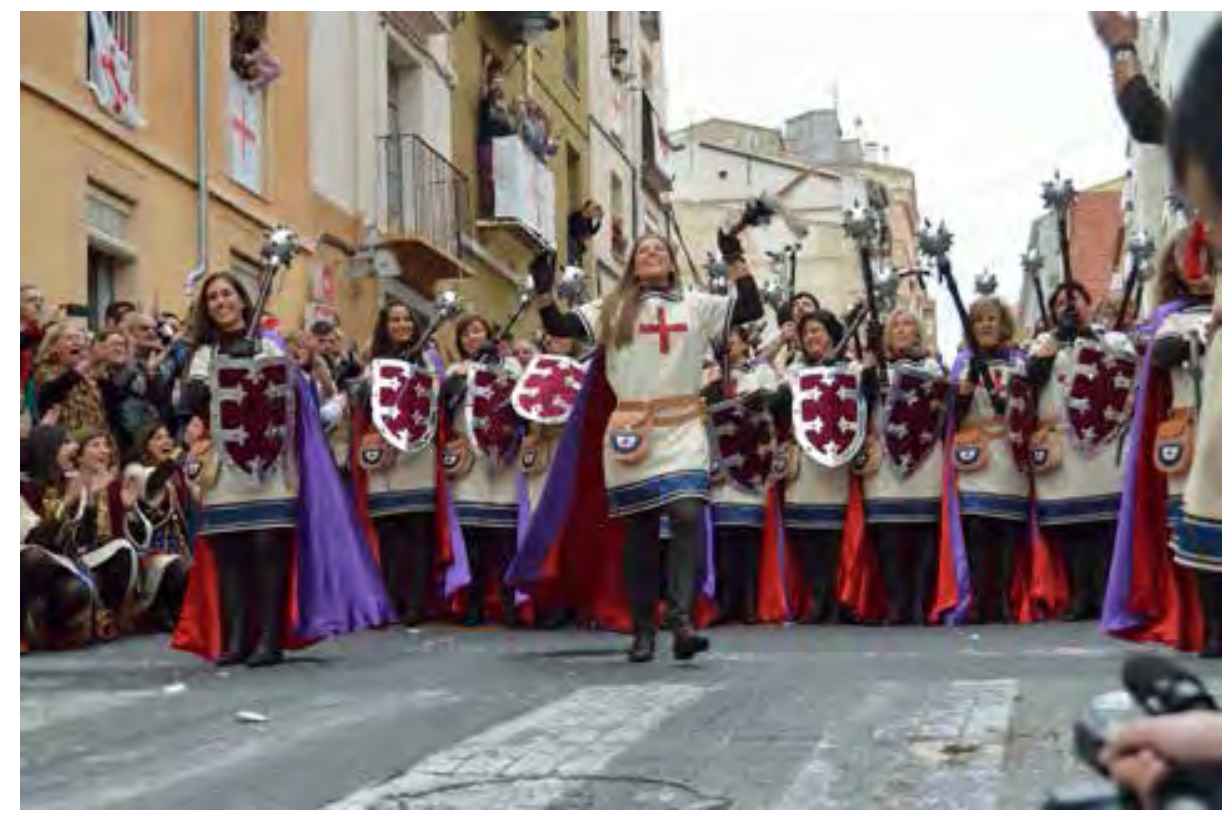

Filá Vascos en Alcoy(Alicante). Xe que foto

"la doncella guerrera" en el que una mujer, vestida de hombre, lucha como un héroe más (Rodríguez-Baltanás, 1989:51-62).

El travestismo estratégico siempre ha estado presente como parte de una estratagema militar o para tomar el lugar del marido fallecido o de la figura de hombre ante la guerra. Sigamos poniendo ejemplos dentro de España; en el siglo VIII, las mujeres de la población de Orihuela, al no encontrarse sus maridos, se vistieron con los trajes de estos y, cogiendo las armas, se colocaron en las murallas cuando vieron llegar al ejército de Abdalaziz; lo mismo pasó en Ávila ante el ataque de los almorávides en el siglo XII donde las mujeres también se vistieron organizadas por Jimena Blázquez; un siglo más tarde en la población jienense de Martos ante el ataque del rey musulmán de Arjona; o en Palencia a finales del siglo XIV (Lorenzo, 2003: 83-95). Pero no debemos olvidarnos de Juana de Arco, la mujer que se travistió de hombre dirigiendo la defensa de Francia con tan solo trece años (Wohl, 2004).

En el caso de la figura de la mujer en fiestas, el argumento patriarcal y falocentrista siempre ha estado presente. Dejando a un lado su papel como transmisora de la riqueza gastronómica y del arte culinario unido a las fiestas de moros y cristianos (Martínez, 2014b), desde el siglo XIX, la mujer solía participar inmóvil en carrozas en las fiestas locales cuyo papel se sintetizaba en saber estar, ser ellas y pasivas. Su participación dentro de las fiestas de moros y cristianos comenzó a partir de la figura de "cantineras" siendo imitación de las cantineras militares que acompañaban al ejército. Son citadas, en las fiestas del levante en Petrer en 1870, en Jijona cuatro años más tarde, en Onil en 1886 o en Villena en 1890 y en Andalucía en las fiestas del anejo cullarense de Matián (Cabeza y Martínez, 2012). Su incorporación con cargos comenzó en Onil en 1886, como capitana y en Petrer en 1905 como abanderada rompiendo así con la tradición (Martínez, 2015c: 81). Entre 1926 o 1927, en Muro, se tiene constancia de una escuadra formada por cinco mujeres con una mujer como cabo de escuadra que desfilaron en la capitanía de la Filà Llana. En 1928 el periódico alcoyano "El Noticiero Regional" publicó la fotografía de esas mujeres en compañía del capitán (Pascual, 1994). Durante el siglo XX, esta empezó a tomar cierta importancia dentro de la fiesta, especialmente a partir de los años 60-70 más bien en pueblos que en ciudades 


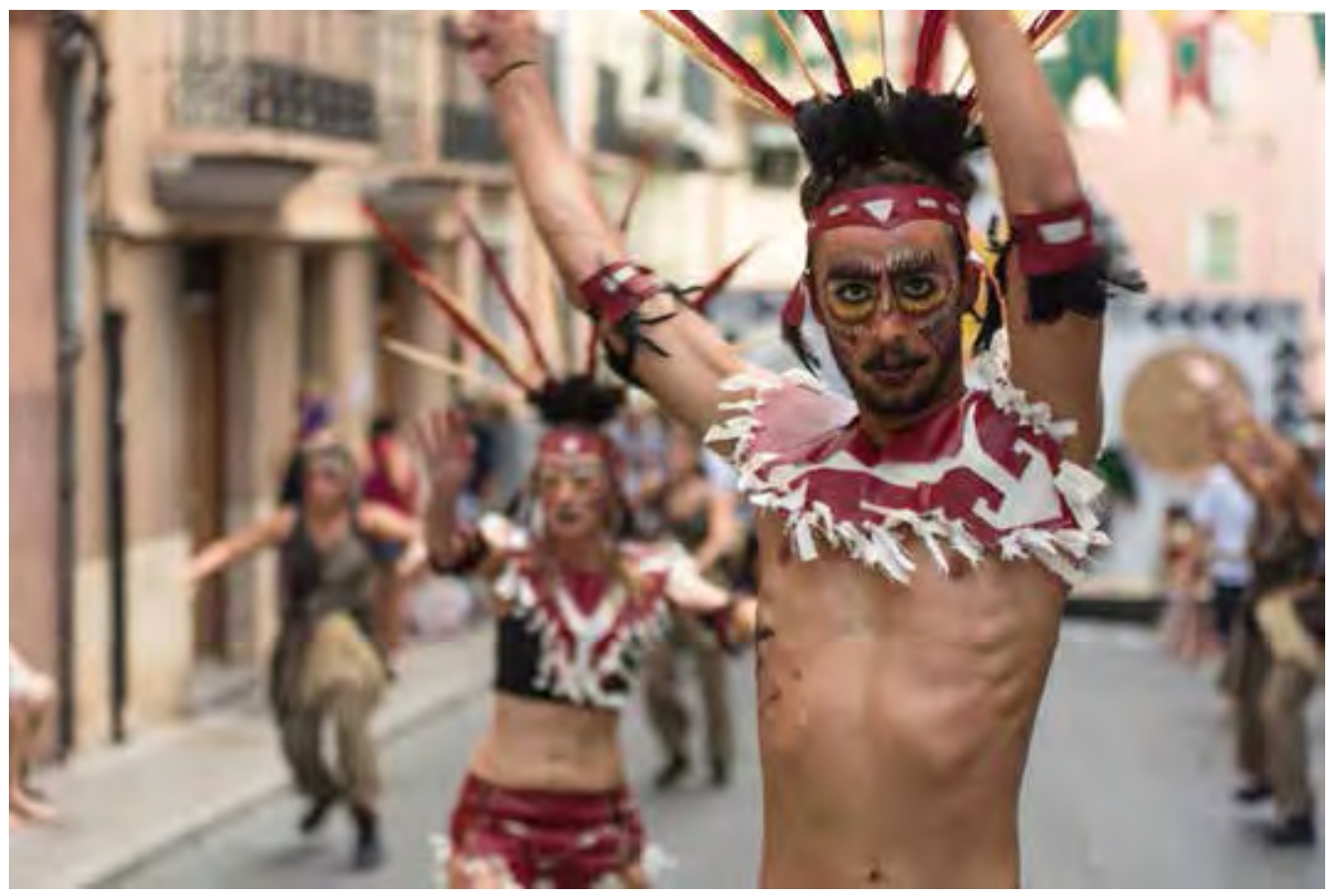

Momento en las fiestas de Xixona. Xe que foto

donde costó más trabajo su integración y aceptación ocasionando diferentes puntos de vista (Martínez, 2015c: 79-87).

Su incorporación comenzó, en un principio, porque esta aportaba mayor número de festeros, mayor número de cuotas y, por consiguiente, un engrandecimiento de la fiesta y un reparto de gastos pero, bien es cierto que, cuando han visto en peligro sus fiestas, han sido capaces de tomar la iniciativa llegando a desplazar al propio hombre como fue el caso de la tía Ramona, en Petrer (Chico, 1974: 247):

"Por otra parte, el travestismo fue muy solicitado en el teatro del Renacimiento y del Barroco, donde el traje de hombre proveía a la fémina de un salvoconducto para deambular sin llamar la atención en una sociedad que la condenaba al monótono espacio doméstico, al convento o, en el peor de los casos, al viciado ambiente del prostíbulo [...] Tanto el teatro isabelino inglés como la comedia barroca española están plagados de mujeres travestidas" (Gutiérrez, 2013:100$101) .^{5}$

No debemos obviar, por tanto, que también nos encontramos con un travestismo escénico donde, la falta de actores varones, incorpora a la mujer desempeñando el rol que le correspondió a aquéllos "por tradición" o "desde siempre” tal y como argumentan los más puristas o bien, es utilizado este travestismo para su introducción en la fiesta o en cargos considerados "inamovibles". Es así cómo nos encontramos con mujeres representando roles masculinos en la localidad almeriense de Sierro donde Beatriz Rubio hizo de Embajador

5 Aun así hay que recordar que, durante el siglo XVI, fueron emitidos varios decretos que impedían salir en escena a las mujeres teniendo que ser representados todos los papeles por hombres (Ferrer, 2012), 
moro en el año $2006^{6}$ o incluso la escenificación del rey de las tinieblas, Lucifer, en 2009, por parte de una mujer como fue el caso del anejo Balax-El Rejano de Caniles (Granada). Es de especial mención, en la Comunidad Valenciana, el caso de Elche donde Fina Quiles, perteneciente a la Filà Boscos, desempeñó el papel de Capitán cristiano en 1999 compartiendo las capitanías con Julián Fernández como Capitán moro, de la Comparsa Las Huestes del Califa. Este hecho ocasionó la baja de la comparsa Caballeros Halcones quienes no apoyaron la decisión aprobada por la AFMYCE. La incorporación de la mujer (niñas) también se dio a través del papel de Ángel, Ángel de Rodella o Paje escenificado hasta mediados del siglo XX principalmente por niños y en soldadescas de pueblos como es el caso de la localidad granadina de Orce utilizando trajes del servicio militar de sus familiares por poner algunos ejemplos (Martínez, 2016). Pero su incorporación no es del todo fácil y un ejemplo de ello recientemente es en 2012 y 2016, en El Campello, donde fueron propuestas unas mujeres, primero por Tercio de Flandes y después por Cavallers de Conquesta, para que ostentasen la capitanía y cuyas proposiciones fueron rechazadas, tras una votación desde la Junta Festera. ${ }^{7}$

A finales de la dictadura franquista o bien entrada la democracia española y haciendo mención a la introducción de mujeres en comparsas nos encontramos con casos donde la mujer formó parte desde un principio de la creación de las comparsas, como pasó en Cieza, en la Región de Murcia en los años 90 del siglo XX, o en la población de Benamaurel de la Comunidad Autónoma Andaluza en 1978, siendo su papel de gran importancia para el engrandecimiento de sus fiestas confeccionando los primeros trajes, desfilando en escuadras y asumiendo cargos directivos siendo ejemplo para localidades colindantes (Martínez, 20082009-2012). Adentrándonos en la Comunidad Valenciana, aunque en algunas poblaciones como Lluxent desde 1978 la mujer formó parte de la fiesta en igualdad de condiciones con el hombre (García, 2016: 73-76), en la localidad alicantina de Villena, la incorporación de esta fue determinada a partir de una demanda judicial presentada en el Juzgado de Primera Instancia de Villena obteniendo sentencia favorable el día 12 de noviembre de 1987 desfilando, por primera vez, al año siguiente en prácticamente todas sus comparsas. Villena influyó en otros pueblos como es el caso de Ontinyent (1989) y Concentaina (1993). Es de especial mención la ciudad de Alcoy, fiesta de Interés Turístico Internacional, pues no es hasta el año 2015 cuando una escuadra femenina participa en la diana de la mano de la Filà Marrakesch a los sones del pasodoble Krouger de Camilo Pérez Laporta y, en 2016, cuando por medio de la Filà Vascos, acompañada por la marcha cristiana El Conqueridor de José María Valls Satorres y la Filà Marrakesch participen en una Entrada oficial. No menos importante es la incorporación también de la mujer, en los últimos años, en actos tan representativos como la arcabucería (Martínez, 2014: 118).

Y estos progresos tan importantes para una sociedad democrática como es la española se han ido forjando mayoritariamente en las últimas décadas desde la aprobación de la Constitución Española de 1978 que supuso un cambio y un avance en el que se aborda la igualdad entre hombres y mujeres y la libertad e igualdad de las personas. ${ }^{8}$

6 También hay que hacer mención que esta población con tan solo cuatrocientos habitantes, en 2016, su "Relación" es representada en su totalidad por mujeres escenificando a personajes masculinos.

7 Es de destacar, a su vez, que dentro del régimen interno de la asociación se establece desde febrero de 2015 en su número 5 que el cargo de embajador lo desempeñará un "hombre mayor de 18 años".

8 Algunos de los artículos de la Constitución de 1978 a destacar son:

Artículo 9.2.- Corresponde a los poderes públicos promover las condiciones para que la libertad y la igualdad del individuo y de los grupos en que se integra sean reales y efectivos; remover los obstáculos que impidan o dificulten su plenitud y facilitar la participación de todos los ciudadanos en la vida pública, económica, cultural y social.

Artículo 10.1.- La dignidad de la persona, los derechos inviolables que le son inherentes, el libre desarrollo de la personalidad, el respeto a la ley y a los derechos de los demás son fundamento del orden político y la paz social. 


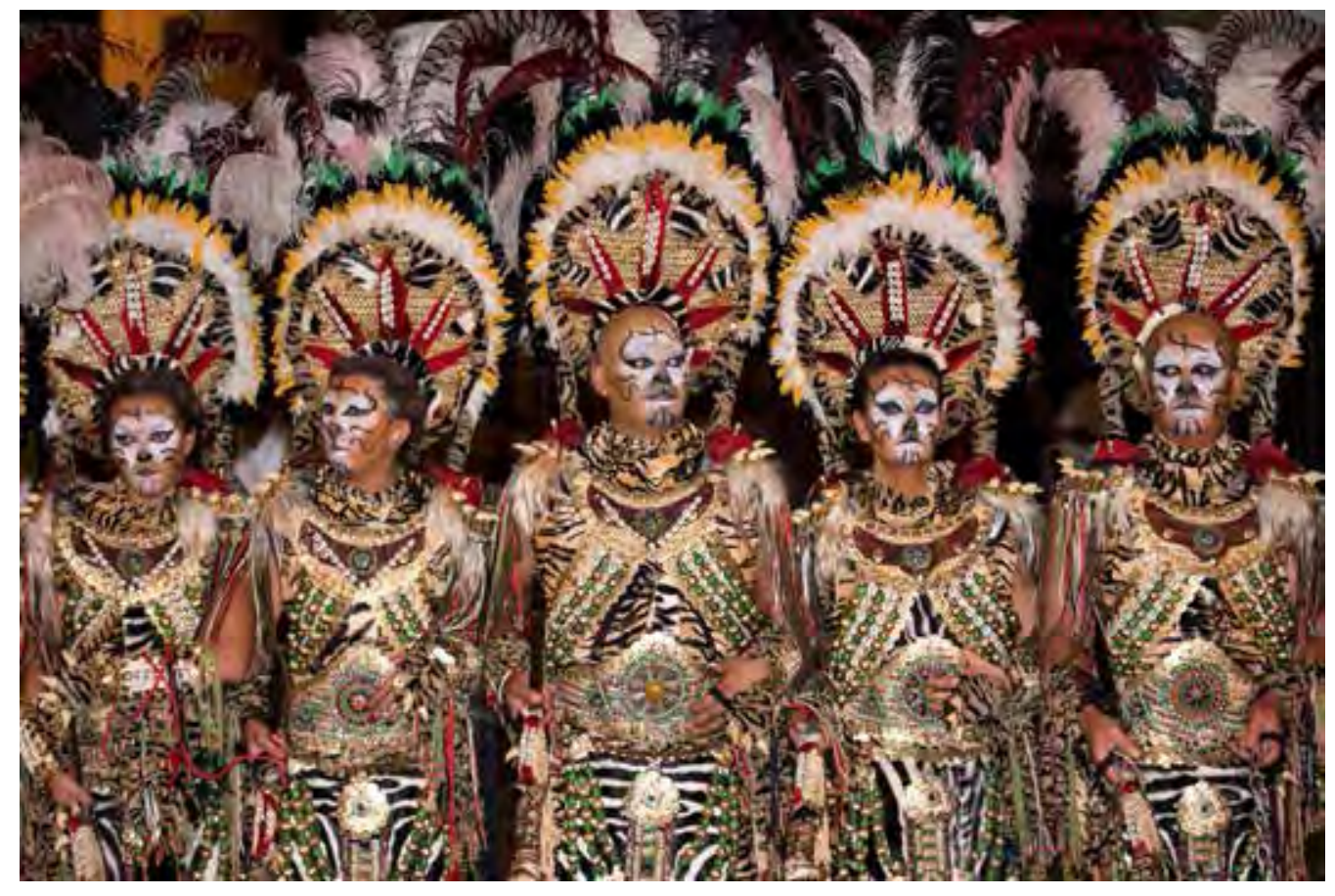

\section{Escuadra mixta en Xixona (Alicante). Xe que foto}

\section{Conclusiones}

Considerada una fiesta de hombres por su carácter caballeresco vinculado al mundo de la caza y del servicio militar con reminiscencia guerrera, entrada la democracia y la postmodernidad, en las fiestas de moros y cristianos el espacio público se ha convertido en un soporte del arte donde se despliega la creatividad y, dentro de él, el cuerpo de protagonistas y espectadores se conforman como el principal soporte de la performance. La influencia del cine así como del teatro contemporáneo ha creado figuras que han comenzado a formar parte de una nueva estética y cultura dentro de las entradas, botas o desfiles. Alrededor de la fiesta y rompiendo con ideas falocentristas forjadas a lo largo de los siglos surgieron, de manera subconsciente para sus protagonistas, seres andróginos así como diferentes tipos de travestismos (recreativo, escénico y estratégico). A su vez, la fiesta por sí misma, se convierte en un lugar de encuentro de valores, tanto éticos como cívicos, así como un espacio para la propia búsqueda de igualdad entre géneros. ${ }^{9}$

Artículo 10.2.- Las normas relativas a los derechos fundamentales y a las libertades que la Constitución reconoce, se interpretan de conformidad con la Declaración Universal de los Derechos Humanos y los tratados y acuerdos internacionales sobre las mismas materias ratificadas por España.

Artículo 14.- Los españoles son iguales ante la ley, sin que pueda prevalecer discriminación por razón de nacimiento, raza, sexo, religión opinión o cualquier otra condición o circunstancia personal o social.

Artículo 23.1. Los ciudadanos tienen derecho a participar en los asuntos públicos, directamente o por medio de representantes, libremente elegidos en elecciones periódicas por sufragio universal.

9 Muchas localidades han quitado las reinas y damas de fiestas, como es el caso de Castalla en la provincia de Alicante en 2016, o bien las han integrado dentro de las propias capitanías festeras, como por ejemplo la población de Benamaurel en Granada, e incluso, en el caso de Villena, se ha permitido a los hombres también ser regidores de fiestas. 
Finalmente aclarar que, aun siendo España el país más tolerante del mundo y pionero en la lucha contra la homofobia ${ }^{10}$ (Paradinas, 2016), en ningún caso, a través del siguiente artículo, nos referimos al valor designativo primario de travestismo relacionado con una orientación sexual determinada, sino tal y como nos argumenta el filólogo José Ismael Gutiérrez:

"Al arte y a la ficción, por cuanto, en un nivel más profundo toda obra de creación construye un universo paralelo donde se simula/disimula el verdadero rostro de su creador, cubriendo de un barniz de ilusoria verdad una mentira (personajes, historias, lugares descritos...) que a veces tiene tintes de real" (Gutiérrez, 2009: 31).

Hablar de fiestas de moros y cristianos no es hablar de un momento histórico concreto. Como la piel de un camaleón, esta fiesta se ha adaptado y, en vez de restar, ha ido sumando. ${ }^{11}$

\section{Bibliografía}

ALBERT-LLORCA, M. y GONZÁLEZ ALCANTUD, J.A.

2003 Moros y cristianos. Centro de Investigaciones Etnológicas “Ángel Ganivet” Diputación Provincial de Granada. Granada.

ANTA FELEZ, J.L.

2003 "Violencia, comunidad y complejidad: moros y cristianos en Carchelejo (Jaén)" en ALBERT-LLORCA, M. y GONZÁLEZ ALCANTUD, J.A.: Moros y cristianos. Centro de Investigaciones Etnológicas “Ángel Ganivet” Diputación Provincial de Granada. Granada.

ANTA FÉLEZ, J.L. y MARTÍNEZ POZO, M.A.

2015 "Las fiestas de moros y cristianos como soporte de las artes" en Calle 14. Volumen 10, número 17. Septiembre-diciembre de 2015. Colombia.

ARIZ, L.

1978 Historia de las grandezas de la ciudad de Ávila. Alcalá de Henares (fács: Ávila, Caja General de Ahorros y Monte de Piedad de Ávila). Parte II, 27. f. 44 r. fácsimil.

BAUMAN, Z.

2010 Modernidad líquida. Fondo de Cultura Económica. Madrid.

CABEZA CÁCERES, C. y MARTÍNEZ POZO, M.A.

2012 "La representación de moros y cristianos en Matián (Cúllar, Granada). Una fiesta enterraCARLÉ, M.C. da por el éxodo rural" en Gazeta Antropológica, $n^{\circ} 28$. Granada.

1988 La sociedad hispano medieval. Grupos periféricos: las mujeres y los pobres. Gerdisa. Argentina.

CHICO AMAT, J.

1974 "La mujer y la fiesta", Actas del I Congreso Nacional de Fiestas de moros y cristianos. Villena, p. 247.

DELGADO, $\mathrm{M}$.

2006 “Tiempo e identidad. La representación festiva de la comunidad y sus ritmos” en Jornadas

10 Hecho que es constatable y que ha influido rompiendo el esquema Capitán-Rey-Sultán con Elegida-ReinaSultana en 2016 en la localidad de Guardamar del Segura (Alicante) donde han contado entre sus capitanías con dos sultanes chicos y pareja, pertenecientes a la escuadra Adb-al-Azies, ostentando de esta manera un cargo festero en sus fiestas de moros y cristianos.

11 Las fiestas son una especie de habitáculo sagrado en el seno del tiempo, el equivalente del templo o del monumento en la dimensión espacial, un refugio -o una turbulencia- en que el ser humano dramatiza el sentido último de su existencia como ser social, las condiciones que le hacen posible -aunque sea, como veremos, a la vez que en cierto modo la niegan- y que, además de ser exhibidas como modelos de y para la vida colectiva, son puestas a salvo del desgaste que provoca el paso del tiempo y la acción de los humanos. Eso implica una manipulación del tiempo que lo anula, en el sentido de que lo convierte en reversible lo ahueca, lo agujerea, lo suspende (Delgado, 2006: 78). 
de reflexión en la ciudad festiva. II Jornadas de antropología y religión. Zainak. Bilbao, 26.

DOMENE VERDÚ, J.F.

2015 Las fiestas de moros y cristianos. Publicaciones Universitat d'Alacant. Alicante.

DUARTE GARCÍA, I.

2008 "Representaciones de la muerte en la Edad Media y el Renacimiento" en Ars Médica. Revista de Estudios Médico-Humanísticos, vol 8, $n^{\circ}$ 8. Chile.

FERRER VALLS, T.

2012 "La incorporación de la mujer en la empresa teatral: actrices, autoras y compañías en el siglo de Oro" en 1-25 web. Marzo, 2012. http://entresiglos.uv.es/wp-content/uploads/la-

GARBER, M. rioja.pdf

1992 Vested Interests. Cross-Dressing and Cultural Anxiety. Routledge. London/New York.

GARCÍA ARLANDIS, A.

2016 Origen i evolució de la festa de Moros i Cristians a Lluxent. Edicions Xio Col.leeció el Rafal. Lluxent.

GIL CALVO, E.

1991 Estado de fiesta. Espasa-Calpe. Madrid.

GIL GRIMAU, R.

2000 "Sayyida al-Hurra. Mujer marroquí de origen Andalusî” en Anaquel de Estudios Árabes. Año 2000.

GUTIÉRREZ, J.I.

2009 Identidad y simulación. Ficciones, performances, estrategias culturales. Advana Vieja. Valencia.

2013 Del travestismo femenino. Realidad social y ficciones literarias de una impostura. EditoHEUZÉ, L. rial Academia del Hispanismo. Pontevedra.

2003 "Las mujeres en las fiestas" en ALBERT-LLORCA, M. y GONZÁLEZ ALCANTUD, J.A.: Moros y Cristianos. Diputación de Granada. Centro de Investigaciones Etnológicas "Ángel Ganivet". Granada.

HOMOBONO MARTÍNEZ, J.I.

2004 "Fiesta, ritual y símbolo: epifanías de las identidades" en Jornadas de reflexión en la ciudad festiva. II Jornadas de Antropología y religión. Zainak, 26.

HURTADO DE MENDOZA, D.

$1970 \quad$ Guerra de Granada. Clásicos Castalia. Madrid.

JEAN-PIERRE, A.

2003 "La ilusión de la fiesta" en ALBERT-LLORCA, M. y GONZÁLEZ ALCANTUD, J.A.: Moros y cristianos. Centro de Investigaciones Etnológicas “Ángel Ganivet” Diputación Provincial de Granada. Granada.

LORENZO ARRIBAS, J.

2003 "Tampoco acariciaron banderas. Apuntes críticos sobre las mujeres y la guerra medieval" en NASH, M. y TAVERA, S.: Las mujeres y las guerras. El papel de las mujeres en las guerras de la Edad Antigua a la Contemporánea. Ed. Icaria. Barcelona.

MANSANET RIBES, J.L.

1976 "La fiesta de moros y cristianos como institución y su ordenación" en Actas del I Congreso Nacional de Fiestas de moros y cristianos. Villena.

1976b "Lo espiritual y su proyección en la fiesta" en Actas del I Congreso Nacional de Fiestas de moros y cristianos. Villena.

MARÍN VALDIER, R. (Coord.)

2003 Didáctica de la Educación Artística. Pearson Education. Madrid.

MÁRMOL CARVAJAL, L.

1991 Rebelión y castigo de los moriscos. Arguval. Málaga.

MARTÍNEZ POZO, M.A.

2008 Descubre el origen... Fiestas de moros y cristianos en la Comarca de Baza. Imprenta Cervantes, Baza. 
2009 En busca de la verdad... Fiestas de moros y cristianos en la Comarca de Baza. Imprenta Cervantes, Baza.

2012 Fiestas de moros y cristianos en España. Grupo de Desarrollo Rural del Altiplano de Granada y Excmo. Ayuntamiento de Benamaurel. Baza.

2013 Escuela, docentes y fiestas de moros y cristianos en el Antiguo Reino de Granada. Ed. Círculo Rojo. Almería.

2014 "El fuego y la pólvora en las fiestas de moros y cristianos" en El Filandar-O Fiadeiro. Publicación Ibérica de Antropología y Culturas Populares, $n^{\circ}$ 21. p. 111-121.

2014b "Gastronomía, arte culinario y bebida en las fiestas de moros y cristianos" en Revista Folklore, 394. p. 11-22.

2015 Moros y cristianos en el mediterráneo español. Antropología, educación, historia y valores. Ed. Gami. Granada.

2015b "El fallecimiento de festeros en localidades con fiestas de moros y cristianos" en Revista Folklore, 403. p. 83-93.

2015c "La mujer en las fiestas de moros y cristianos" en Antropología experimenta, 15. Universidad de Jaén. Jaén. p. 79-87.

2016 "Fiestas de moros y cristianos de Orce en honor de San Antón y San Sebastián. Fusión de personajes, simbolismos, tradiciones y actos" en Revista Folklore, 411. p. 4-32.

NASH, M y TAVERA, S.

2003 Las mujeres y las guerras. El papel de las mujeres en las guerras de la Edad Antigua a la PALENCIA, L.

2008 Hollywood queer. T\&B Editores. Madrid.

PARADINAS, $\mathrm{M}$.

2016 El fin de la homofobia. Derecho a ser libres para amar. Fibgar y Catarata. Madrid.

PASCUAL GISBERT, J.J.

2016 "Les festes de Moros i Cristians de Muro" en Revista de Festes. Junta de Festes 1994. Muro.

PÉREZ DE COLOSIA RODRÍGUEZ, M.I.

1989 "Represión inquisitorial después de la guerra de las Alpujarras" en Boletín Estudios de Arte, Geografía e Historia, 12. Málaga. pág. 215-238.

RODRÍGUEZ-BALTANÁS, E.

1989 "El Romancero, ¿femenino o feminista? Notas a propósito d la doncella guerrera” en Draco, Revista de Literatura. p. 51-62.

ROLDÁN RAMÍREZ, J.

2003 "Emociones reconocidas. Formación, desarrollo y educación de las experiencias estéticas" en MARÍN VALDIER, R. (Coord.): Didáctica de la Educación Artística. Pearson Education. Madrid, 2003.

SCHECHNER, R.

2000 Performance: Teoría y prácticas interculturales. Trad. M. Ana Díaz. Libros del Rojas y

TURNER, V. Universidad de Buenos Aires. Buenos Aires.

1988 El proceso ritual: estructural y antiestructura. Taurus. Madrid.

WILDE, O.

1987 "La decadencia de la mentira" en Ensayos. Artículos. Trad. Julio Gómez de la Serna. HysWOHL, L. de pamérica Ediciones S. A. y Ediciones Orbis S.A. pág. 101-142.

2004 Juana de Arco. La chica soldado. Ediciones Palabra. Madrid. 